\title{
The Familial Mediterranean Fever from the modern postnonclassic scientific viewpoint
}

\author{
Armen Nersisyan ${ }^{* 1}$, Konstantin Danielyan ${ }^{1}$ and Eduard Nazaretyan ${ }^{2}$
}

\author{
Address: ${ }^{1}$ National Institute of Health of the Republic of Armenia, Armenia and ${ }^{2}$ Department of Internal Diseases 1 Center FMF, Armenia \\ * Corresponding author
}

from International Society on Brain and Behaviour: 2nd International Congress on Brain and Behaviour

Thessaloniki, Greece. 17-20 November 2005

Published: 28 February 2006

Annals of General Psychiatry 2006, 5(SuppI I):SI 29 doi:I0.1 186/I744-859X-5-SI-SI 29

\begin{abstract}
Background
The Familial Mediterranean Fever (FMF) as a genetic disease with autosom-recessive transmitting mechasnism and a clinical unclear, enigmatic, aimlesely spread aseptic inflammation finds a new solution from the viewpoint of psychosomatic theory [1], where are covered integral (psychic, phisical), hierarchic, selfregulatory, selfdecveloping and selforganizing approaches. Somatoform disorders which exist among all the patients suffering from FMF [2] according to the modern FMF classification are not diagnosed and treated in time which is the reason for the progress of this disease as far as the internists diagnosed FMF only in case of availability of aseptic inflammation.
\end{abstract}

\section{Materials and methods}

Aseptic inflammmation [3] is connected with the consequence of the traumas borne in the past which are realized in the unfavourable conditions of the present life, when the disease is gradually deepening as mentioned above. The aseptic inflammation according tothe self regulating mechanism of the organism is the replying reaction to the trauma, which is becoming more and more frequent, as the aptients suffering from FMF and having bad psychological defensive mechanisms are adapted to the exteriorworld with difficulty. The frequently processing unregulatory aseptic inflammations represent a great danger for the regulationof homeostasis, which according to the approach of self-regulatio the body responses with overspread ameloidosis.

\section{Results}

The deepening of ameloidosis which leads to the death of the patients, strengthens the patient's hopelessness in the struggle for life, as they know that they are suffering from incurable disease and can see the how ends ameloidosis on their relatives. Thus the system leads him to death, dis- arrangement of the desorganism, development of enthropy.

\section{Discussion}

The dynamic process - the system can be regulated with psychotherapy, bringing the system to regulation, the dicrese if enthropy, the disappearance of the attacks and the prevention and treatment of ameloidosis, which can be observed among our recovered patients.

\section{References}

I. Nersisian A, Danielyan K: About The Interrelation Of Periodic Disease And Psychosomatic Disorders - Trauma and Recovery. 6th Congress for Bridging Eastern and Western Psychiatry Abstracts And Papers, October 10-12, 2003, Yerevan .

2. Nersisian A: A new Approach of FMF. Advances in Psychiatry Abstracts Issue, March 12-15, 2005, Athens, Greece .

3. Danielyan K, Nersisian A: The role of Somatoform Disorders in the Genesis of Periodic Disease (FMF). 18th Panhellenic Congress of Psychiatry Abstracts Issue, May 14-18, 2004 Kos . 